Revista Brasileira do Esporte Coletivo - v. 2. n. 2. 2018.

\title{
Artigo original \\ CENTRO LIMOEIRENSE: MEMÓRIAS DE UM CLUBE CENTENÁRIO CENTRO LIMOEIRENSE E O FUTEBOL
}

\author{
${ }^{1}$ Luan Piettro Henrique do Nascimento; ${ }^{2}$ Marcellus Brito de Almeida; ${ }^{3}$ Thiago de Amorim \\ Carvalho.
}

\begin{abstract}
RESUMO
Introdução: O Centro Limoeirense frui de uma rica história, digna de ser resgatada, refletida e divulgada, pois, essa trajetória interferiu, significativamente, nos aspectos sociopolíticos e cultural da população interiorana de Pernambuco. Objetivo: Resgatar e descrever algumas das centenárias memórias do Centro Limoeirense. Método: Trata-se de uma pesquisa documental do tipo descritiva, uma vez que as informações obtidas, na sua maioria, foram oriundas de fontes primárias como o estatuto do clube, fotografias de acervos particulares e outros registros escritos. Resultados e discussão: Dentre os documentos analisados, foi possível observar que o Centro Limoeirese é originado da junção de dois clubes da cidade de Limoeiro. Ao longo de sua história foi se desenvolvendo e hoje contém uma estrutura adequada para a prática da modalidade em todos os escalões. Conclusão: A realização desse estudo possibilitou entender o surgimento do Centro Limoeirense, bem como a sua trajetória desde sua fundação até a atualidade.
\end{abstract}

Palavras-chave: Futebol, Centro Limoeirense, Histórias.

\section{Centro Limoeirense: memories of a centenary club.}

\section{ABSTRACT}

Introduction: The Centro Limoeirense has an excellent history, worthy of being rescued, reflected and divulged, because this trajectory significantly interfered in the socio-political and cultural aspects the population of Pernambuco. Objective: Rescue and describe some of the centennial memories of the Centro Limoeirense. Method: It is a documentary research of the descriptive study, since the information obtained, for the most part, came from primary sources such as club status, photographs of private collections and other written records. Results and discussion: Among the documents analyzed, it was possible to observe that the Center Limoeirese is originated from the junction of two clubs of the city of Limoeiro. Throughout its history, it has developed and today it contains adequate structure for practice of the modality in all the categories. Conclusion: The realization of this study allowed us to understand the emergence of Center Limoeirense, as well as its trajectory since its foundation to the present.

Key words: Soccer, Centro Limoeirense, Stories.

\footnotetext{
12 Centro Acadêmico de Vitória da Universidade Federal de Pernambuco (CAV-UFPE).

${ }^{3}$ Centro Acadêmico de Vitória da Universidade Federal de Pernambuco. Centro Universitário

Brasileiro. (UNIBRA).

Endereço: Rua Afonso de Melo, S/N, Loteamento Jardim Santa Rosa, Feira Nova/PE.

E-mail: luan.piettro@gmail.com; marcelus71@hotmail.com; tac_thiago@hotmail.com.
} 
Centro Limoeirense e o futebol

\section{INTRODUÇÃO}

O epíteto de país do futebol é facultado ao Brasil, devido os resultados expressivos alcançados pela seleção brasileira no cenário esportivo mundial. A sociedade brasileira é influenciada culturalmente, socialmente e economicamente pelo futebol desde que Charles Miller, regressou da Inglaterra e trouxe materiais esportivos necessários a prática da modalidade (MILLS, 2005). Miller não presumia o impacto que esse fenômeno esportivo fosse causar a população brasileira, dado que o futebol adquiriu caráter de funcionalização, sociabilização, ideologização, mercadorização e espetacularização (PIRES, 1998).

A priori a modalidade, no Brasil, era uma prática elitizada cultivado apenas pela classe dominante e pela colônia inglesa em São Paulo, sem acesso à população como um todo. Ao decorrer do tempo foi perdendo o caráter elitista sendo a prática do futebol democratizada. A democratização fez com que começassem a surgir campos nas várzeas e nos terrenos baldios e equipes de futebol foram se formando (ANTUNES, 1992). O mesmo autor, ainda, enfatiza que "o fascínio pelo futebol fez com que trabalhadores começassem a se organizar e a criar seus clubes no próprio local de trabalho, batizandoos com o nome da fábrica e conquistando o apoio dos patrões" (ANTUNES, 1992).

Com a crescente prática da modalidade, e sua consequente expansão, 0 futebol começou a se difundir e os clubes foram surgindo em todas as regiões e estados do país. Vale ressaltar que os primeiros clubes fundados diretamente com objetivo de praticar o futebol foram o Sport Clube Rio Grande fundado no estado do Rio Grande do Sul e a Associação Atlética Ponte Preta fundada em Campinas, no estado de São Paulo, ambos foram fundados no ano de 1900 e que atualmente permanecem ativos (MÁXIMO, 1999).

Atualmente, no Brasil há inúmeros clubes de futebol, centenários e bemconceituados, que afirmaram sua identidade cultural, política, econômica, étnica e territorial no cenário nacional com suas particularidades, especificidades e histórias de superação e conquistas. A título de exemplo: Botafogo de Futebol e Regatas, Clube Atlético Mineiro, Clube de Regatas do Flamengo, Clube de Regatas Vasco da Gama, Associação Atlética Ponte Preta, Santos Futebol Clube, Sociedade Esportiva Palmeiras, Sport Club Corinthians
Paulista, Fluminense Football Club, Grêmio Foot-Ball Porto Alegrense, Sport Club Internacional (CONFEDERAÇÃO BRASILEIRA DE FUTEBOL, 2009).

Em Pernambuco, também temos clubes centenários, cada um com sua identidade própria e relevância para o estado e seus adeptos, como o Clube Náutico Capibaribe, Santa Cruz Futebol Clube, Sport Clube do Recife, América Futebol Clube e o Centro Limoeirense. O Centro Limoeirense é o clube de futebol mais antigo do interior pernambucano e o terceiro clube de futebol a nascer no estado. Sendo mais jovem que o Sport Club do Recife (1905) e Clube Náutico Capibaribe (1901) e mais velho que o Santa Cruz Futebol Clube (1914) (CONFEDERAÇÃO BRASILEIRA DE FUTEBOL, 2009).

Completados 105 anos, o Centro Limoeirense frui de uma rica história construída pelos seus idealizadores, gestores, treinadores, atletas, patrocinadores, sócios e torcedores de Limoeiro e cidades circunvizinhas que é digna de ser resgatada, refletida e divulgada. Essa trajetória interferiu, significativamente, nos aspectos sociopolíticos e culturais dessa população interiorana, movimentando a economia local e atraindo, especialmente em dias de jogos, moradores de municípios de toda a região, como se constata nas datas de realização desses eventos esportivos (ANDRADE, J. N.; COSTA, B., 2013).

Considerando a importância do futebol para a Limoeiro e cidades circunvizinhas, no auxílio da constituição de sua identidade ao longo do tempo, faz-se necessário sistematizar e descrever sobre a história de um dos clubes centenários do estado de Pernambuco. Nesse sentido, o presente estudo busca preencher um lapso no campo da história do futebol pernambucano, uma vez que não se possui material cientifico-acadêmico que aborde a temática. Portanto, o objetivo deste estudo é resgatar e descrever algumas das centenárias memórias do Centro Limoeirense.

\section{MÉTODO}

O procedimento metodológico adotado para a realização deste estudo foi à pesquisa documental, na qual as fontes consultadas foram os arquivos históricos do Centro Limoeirense como jornais, revistas, arquivos históricos, livros, diários de ponto, ata de assembleias, dados estatísticos, biografias. As etapas utilizadas para o desenvolvimento da pesquisa foram: localização das fontes, 
obtenção do material e a análise e interpretação dos dados que se deram por meio de leituras exploratória, seletiva e analítica. Na fase exploratória realizamos uma leitura prévia do material, com a finalidade de verificar a importância da obra para a pesquisa, seguidamente selecionamos os materiais que respondesse os objetivos da pesquisa e por fim uma leitura analítica, onde compreendemos e ordenamos as informações obtidas nas fases anteriores.

\section{RESULTADOS E DISCUSSÃO}

\section{A alvorada do Centro Limoeirense}

No ano em que a "Princesa do Capibaribe", como era conhecida a cidade de Limoeiro, comemorava seus vinte anos de emancipação, líderes esportivos almejavam um clube futebolístico de maior expressão para a cidade. Exatamente, aos quinze dias do mês de setembro do ano de mil novecentos e treze, reuniram-se representantes provenientes do Gabinete de Leitura Machado de Assis (fundado em 1909) do Clube Dragões Limoeirenses (fundado em 1910) com o objetivo de se fundirem e fazer com que surgisse um novo clube de futebol. Assim surge o Centro Limoeirense, a primeira associação futebolística do interior pernambucano. Até então havia apenas associações sediadas na capital do estado (PEREIRA, 2013).

Seguidamente, reuniões foram marcadas para ser definida a gestão do clube, chegando ao consenso que os centristas seriam administrados pelos senhores Oscar Vareda, Jerônimo Lima, Teófilo Gomes de Oliveira, José Vareda e Anísio Cadena (VILAÇA, 1971). Todos aspiravam um clube no interior, no qual seus jovens teriam oportunidade de despontarem na modalidade de forma profissional, bem como seus futuros adeptos usufruírem como forma de lazer como, por exemplo, o acompanhamento dos jogos amigáveis e de competições que viriam a serem disputados.

O surgimento do Centro Limoeirense trouxe para seus futuros sócios orgulho e esperança de tempos melhores no cenário futebolístico, visando as seguintes diretivas:

Promover e incentivar a educação física em todas suas modalidades pela realização de provas que concorram para o desenvolvimento físico e apuro eugênico da juventude em ambos os sexos; Promover reuniões e diversões de caráter social, cultural e esportivo, inclusive de esportes profissionais; Dedicar-se a prática do futebol profissional e amador obedecido as exigências contidas na legislação emanada pela FIFA, CBF e FPF e das normas emitidas pelos poderes públicos; Desenvolver e patrocinar, entre seus associados, prática de esportes olímpicos na forma de legislação desportiva de cunho nacional e internacional (CENTRO LIMOEIRENSE, 2011, p. 2).

Apesar de toda expectativa por parte dos idealizadores do Centro Limoeirense e pela população do interior, especialmente, do Agreste na sua sub-região Vale do Capibaribe, o clube não conseguiu impulsionar o futebol profissionalmente, fazendo seu quinquagenário disputando, apenas, campeonatos amadores municipais ou regionais realizados pela liga local. Conseguindo se filiar a Federação Pernambucana de Futebol (FPF) e se profissionalizar em 1963, pode assim participar das competições organizadas pela mesma (VILAÇA 1971; ZIRPOLI, 2013).

No Decorrer de sua história, o Centro Limoeirense foi dirigido por presidentes que contribuíram significativamente para 0 crescimento e desenvolvimento do clube (ver Tabela 1). Podemos destacar Oscar Vareda, seu primeiro presidente, bem como Luiz Gonzaga Duarte, presidente que dirigiu o Centro Limoeirense em seu primeiro ano como clube profissional, Dirson Tavares da Costa, responsável pela reforma da sede social em 1978, José Bernardo Freire Coutinho, presidente centrista por 05 mandatos, José Luiz Freire Mateus presidente na volta do Centro Limoeirense a primeira divisão, José Roberto Rodrigues da Silva, o presidente durante o centenário e Geraldo Hermínio o atual mandatário centrista. 
Quadro 1 - Lista de presidentes do Centro Limoeirense

\begin{tabular}{|l|c|l|c|}
\hline \multicolumn{1}{|c|}{ Lista de Presidentes } & Mandato & \multicolumn{1}{c|}{ Lista de Presidentes } & Mandato \\
\hline Oscar Vareda & 1913 & Jose Bernardino Freire Coutinho & $1983-1985$ \\
\hline Luiz Machado Duarte & N. Inform. & Jose Luiz Freire Mateus & $1986-1988$ \\
\hline José Barbosa de Paula & 1957 & Carlos Alberto Freire Mateus & $1988-1990$ \\
\hline Seráfico Ricardo & 1958 & Pedro Alves De Amorim & $1991-1993$ \\
\hline Luiz Gonzaga Duarte & 1963 & José Wilson Vasconcelos Silva & $1997-1998$ \\
\hline Jose Barbosa Leal & 1969 & Luiz Antônio Teobaldo Cavalcante & $1998-1999$ \\
\hline Joao Correia De Araújo & 1970 & José Burégio De Lima & 1999 \\
\hline Bartolomeu José Machado Fernandes & 1975 & Antônio Da Mota Silveira & 2000 \\
\hline Dirson Tavares Da Costa & 1978 & Paulo José Burégio De Lima & 2001 \\
\hline Jose Xavier Quirino & 1979 & Jaelson Joaquim Barbosa De Lima & 2003 \\
\hline Leuson Santos & 1980 & José Roberto Rodrigues da Silva & $2013-2015$ \\
\hline Adauto Heraclio Duarte Filho & 1982 & Geraldo Hermínio Da Silva & $2015-2018$ \\
\hline
\end{tabular}

Fonte: Arquivo pessoal Centro Limoeirense.

\section{A Rivalidade}

$\mathrm{Na}$ cidade de Limoeiro, o maior rival do Centro Limoeirense é o Colombo Sport Club, fundado em 1918. Enquanto o Centro Limoeirense tinha sua origem popular 0 Colombo era um clube aristocrático, o que alimentou ainda mais essa rivalidade. Histórias dão conta de que nos anos de 1960 a 1980 essa rivalidade era tão descomunal que 0 torcedor do Centro Limoeirense o qual era chamado de centrista, jamais pisaria na calçada do Colombo, assim como o torcedor do Colombo não pisaria nas dependências do Centro Limoeirense (ZIRPOLI, 2013). De acordo com Pereira (2013), ao contrário do Centro Limoeirense, o Colombo nunca chegou a se profissionalizar, com isso só se enfrentavam em partidas amadoras pela Liga Limoeirense de Desportos. Atualmente, o Colombo Sport Club funciona apenas como clube social, já o Centro Limoeirense continua em busca do sonho de retornar a elite do futebol pernambucano.

\section{Os patrimônios do Centro Limoeirense de Futebol}

O clube possui como bens a sua sede e seu estádio (Ver figura 1). Sua sede está localizada na Rua Vigário Joaquim Pinto $\mathrm{n}^{\circ}$ 739, centro, Limoeiro, onde funcionam os serviços administrativos do clube, como os escritórios da presidência, diretoria do clube, secretaria e departamentos administrativos e financeiro. O Centro Limoeirense, assim como outros clubes de menor investimento, principalmente os do interior do estado, além do futebol sempre tiveram outras ações junto à comunidade, em geral, sendo constantemente utilizada para eventos sociais, como bailes, desfiles, bingos, jantares e diversas formas de lazer e/ou entretenimento em sua sede. Seu estádio nomeado José Vareda, mais conhecido em Limoeiro como Varedão, é o local onde o clube manda seus jogos, pertence ao próprio Centro, fica localizado na Rua Epitácio Mateus de Lucena, número 284, no bairro da Pirauira e possui capacidade para cinco mil pessoas (CONFEDERAÇÃO BRASILEIRA DE FUTEBOL, 2016). 
Figura 1- Sede e Estádio José Vareda.

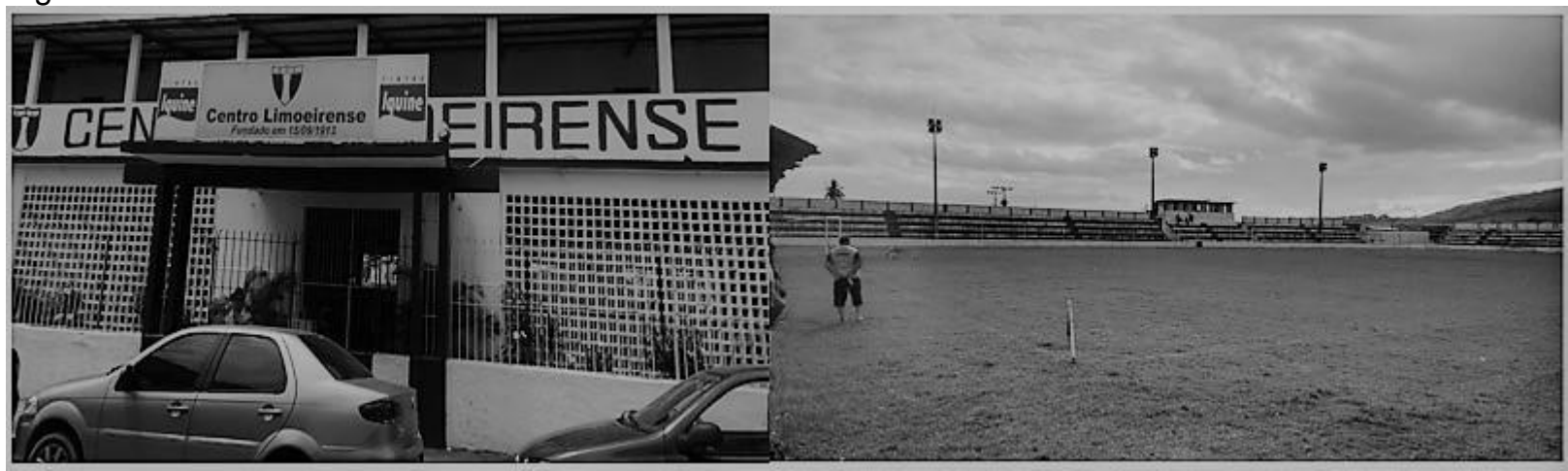

Fonte: Arquivo pessoal Centro Limoeirense

São considerados símbolos máximos do clube, seu escudo, mascote, uniforme (ver figura 2) e o hino. Conforme seu estatuto, as cores oficiais do Centro Limoeirense são vermelho e branco, seu escudo possui um formato romano contendo na parte superior às letras $C L$ em vermelho, onde uma faixa vertical branca separará o escudo em dois hemisférios vermelhos. A mascote é um dragão, que simboliza a força e a fibra que seus jogadores devem incorporar, sua origem se dá, devido o Centro Limoeirense surgir a partir do clube Dragões Limoeirenses, com isso os centristas recebem a alcunha de dragões (CENTRO LIMOEIRENSE, 2011).

Figura 2- Escudo do Centro Limoeirense, Mascote do Centro Limoeirense e Uniforme № 1. 2018.
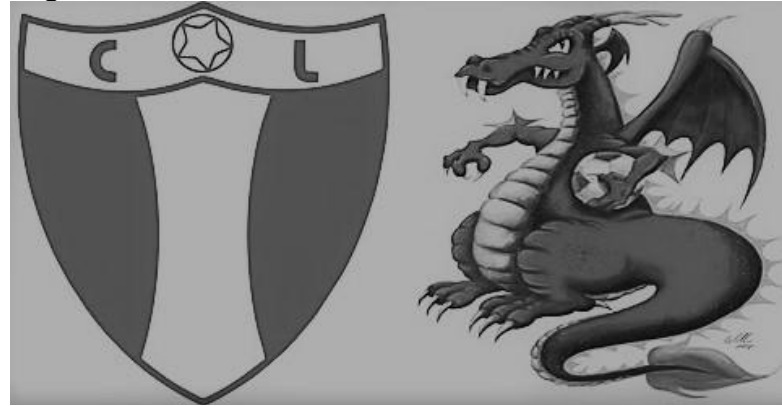

Fonte: Arquivo pessoal Centro Limoeirense

Conforme Prattes (2015), o hino centrista traz a alma do clube estampado, sendo um dos seus símbolos máximos pois expõe a principal alcunha da equipe "o mais querido":

Sou centrista, sou bom / Sou do clube mais querido / $\mathrm{E}$ eu sei $\mathrm{O}$ que digo / Posso até me orgulhar / Se é no campo, ou é na rua ou na sede / Por isso ninguém me impede / Essas cores podem brilhar / Vermelho e branco que traz alegria e emoção / Tenho coração de centrista, o verdadeiro dragão / O nosso Centro é de grande tradição / Sempre honrou Limoeiro na primeira divisão / No Varedão a galera não larga do pé / É o Centro que joga, a torcida é

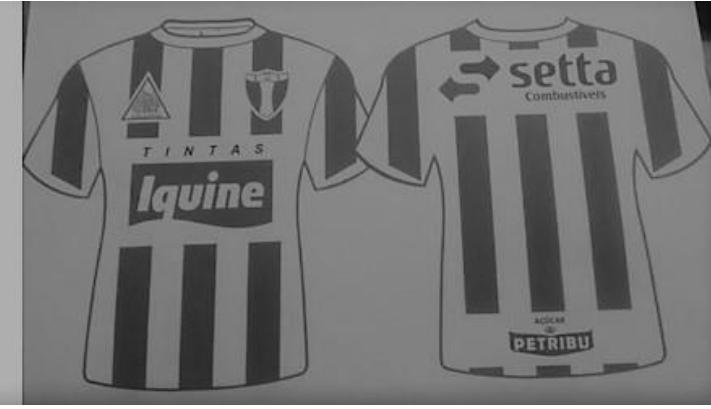

mesmo de fé / Vai ser de pé em pé, vai ser de pé em pé / Com a bola no pé que sai o gol e o olé / Centrista somos todos nós / Centristas somos todos nós / Centristas somos todos nós / Desde os tempos de nossos avós (CENTRO LIMOEIRENSE, 2011).

\section{A trajetória de um clube interiorano.}

Em seu primeiro ano federado e de forma profissional 0 Centro Limoeirense consegue uma façanha, o $5^{\circ}$ lugar no campeonato pernambucano da primeira divisão, sua melhor colocação até os dias atuais. Apesar desse feito, o clube encontrou bastantes dificuldades como qualquer clube do interior no início de sua profissionalização. De 1963 até hoje foram apenas sete participações na primeira divisão do Campeonato 
Pernambucano. Esteve presente ainda em 1964 ficando 30 anos fora da elite pernambucana, voltando a figurar na primeira divisão em 1994, 1996, 1997, 2001 e 2008, sempre mandando seus jogos no estádio José Vareda (ANDRADE, COSTA, 2013).

Vale ressaltar que, na década de 1960

- Campeonato Pernambucano tinha apenas dois clubes do interior, o Central de Caruaru e - Centro Limoeirense. O Centro Limoeirense fez sua primeira partida oficial como clube de futebol profissional pelo Campeonato Pernambucano enfrentando o Clube Náutico Capibaribe no estádio dos Aflitos, em maio de 1963, jogo esse que terminou com derrota do Centro Limoeirense pelo placar de $2 \times 0$. Após a estreia empatou sem gols com o Central de Caruaru na cidade de Caruaru, acumulou mais três derrotas para Santa Cruz, Ferroviário e Sport, após isso conseguiu sua primeira série invicta, de nove partidas, sendo 6 vitórias e 3 empates (ver tabela 2) (PRATES, 2015).

Quadro 2- Primeira série invicta do Centro Limoeirense

\begin{tabular}{|c|c|c|c|c|c|}
\hline \multicolumn{3}{|c|}{ 27/07/1963 - Sábado } & \multicolumn{3}{|c|}{ 01/09/1963 - Domingo } \\
\hline América & $0 \times 1$ & Centro Limoeirense & Centro Limoeirense & $2 \times 0$ & Náutico \\
\hline \multicolumn{3}{|c|}{ 03/08/1963 - Sábado } & \multicolumn{3}{|c|}{ 08/09/1963 - Domingo } \\
\hline Ibis & $1 \times 3$ & Centro Limoeirense & Centro Limoeirense & $2 \times 2$ & Central \\
\hline \multicolumn{3}{|c|}{ 11/08/1963 - Domingo } & \multicolumn{3}{|c|}{ 22/10/1963 - Domingo } \\
\hline Centro Limoeirense & $2 \times 1$ & Ibis & Centro Limoeirense & $1 \times 1$ & Sport \\
\hline \multicolumn{3}{|c|}{ 15/08/1963 - Quinta Feira } & \multicolumn{3}{|c|}{ 13/10/1963 - Domingo } \\
\hline Centro Limoeirense & $2 \times 0$ & Ferroviário & Centro Limoeirense & $2 \times 0$ & América \\
\hline \multicolumn{3}{|c|}{ 25/08/1963 - Domingo } & & & \\
\hline Centro Limoeirense & $0 \times 0$ & Santa Cruz & & & \\
\hline
\end{tabular}

As primeiras vitórias saíram diante do América, do Íbis (2x), do Ferroviário, empatou com o Santa Cruz, venceu o Náutico no José Vareda, empatou novamente com o Central e com o Sport e venceu o América, o que deixou o Centro na $3^{a}$ posição do primeiro turno (ver tabela 3), atrás apenas do Náutico e Sport, que decidiram o primeiro turno vencido pelos alvirrubros da capital, ano que marcou 0 primeiro dos seis títulos do Náutico em sequência, fato este até hoje inalcançável por nenhuma outra equipe no futebol pernambucano (MAGALHÃES, 2018).

Quadro 3 - Classificação primeiro turno Campeonato Pernambucano de 1963.

\begin{tabular}{|c|c|c|c|c|c|c|c|c|c|}
\hline \multicolumn{10}{|c|}{ Classificação } \\
\hline Col. & Equipe & Pontos & $\mathrm{J}$ & V & $E$ & $D$ & GP & GC & SG \\
\hline 1 & Náutico & 22 & 14 & 10 & 2 & 2 & 38 & 14 & 24 \\
\hline 2 & Sport & 22 & 14 & 9 & 4 & 1 & 22 & 8 & 14 \\
\hline 3 & Centro Limoeirense & 16 & 14 & 6 & 4 & 4 & 17 & 12 & 5 \\
\hline 4 & Santa Cruz & 15 & 14 & 5 & 5 & 4 & 18 & 14 & 4 \\
\hline 5 & Central & 13 & 14 & 4 & 5 & 5 & 18 & 17 & 1 \\
\hline 6 & América & 10 & 14 & 4 & 2 & 8 & 17 & 24 & -7 \\
\hline 7 & Ferroviário & 9 & 14 & 3 & 3 & 8 & 15 & 26 & -11 \\
\hline 8 & Íbis & 5 & 14 & 1 & 3 & 10 & 15 & 45 & -30 \\
\hline
\end{tabular}

Já no segundo turno, não saiu como o clube esperava, o rendimento foi muito aquém do obtido no primeiro, apenas duas vitórias sobre o Santa Cruz e contra o América, um empate contra o Sport e sete derrotas, levando assim a equipe a lanterna do turno. $\mathrm{Na}$ classificação geral, foi o sexto colocado, desempenho que se repetiu no ano de 1964 (MAGALHÃES, 2018). A base era composta por: Manguito, Adílson, Dedé, Luizinho, Edmílso, Juvenal, Vi, Tidão, Nélson, Tanzino e Chico (ver figura 3). 
Figura 1 - Primeira equipe do Centro Limoerense a disputar o Campeonato Pernambucano, 1963



Fonte: Arquivo pessoal Centro Limoeirense.

Após isso o clube se retirou das competições oficiais. Retornando na década de 1990, para disputar a primeira divisão estadual em 1994, competição esta que já era mais difundida pelo interior pernambucano, visto que participaram equipes como, Estudantes Sport Club de Timbaúba, Flamengo Esporte Clube de Arcoverde, Clube Atlético do Porto de Caruaru, Associação Desportiva Vitória de Vitória de Santo Antão e Sociedade Esportiva Ypiranga Futebol Clube, de Santa Cruz do Capibaribe. A campanha, no entanto, esteve longe de alcançar bons resultados. Em toda a competição, apenas três vitórias conquistadas (PRATES, 2015).

Em 1995, sagrou-se vice-campeão da série A2 do Pernambucano, perdendo a final para a equipe do Sete de Setembro de Garanhuns. Em 1997 O Centro Limoeirense participou da Série C do Campeonato Brasileiro, seu grupo foi composto por Flamengo de Arcoverde, ASA de Arapiraca e o Juazeiro da Bahia, estreou em pleno José Vareda vencendo o Juazeiro, seguidos de 2 empates contra Flamengo e ASA, no returno perdeu para o ASA, empatou com o Flamengo de Arcoverde e chegou a última rodada com chances de classificação para a próxima fase, uma vitória bastava. Em caso de empate, teria que torcer por uma derrota do Flamengo de Arcoverde para a equipe de Arapiraca. Porém, não contavam com mais uma derrota dessa vez para o Juazeiro, o que o eliminou. 0 Centro Limoeirense terminou a competição na $48^{\circ}$ posição entre os 64 times que participaram. Em seis jogos, venceu um, empatou três e perdeu outros dois (PRATES, 2015).

De volta ao segundo escalão do futebol estadual, o Centro Limoeirense esteve habituado a lutar pelo acesso, disputou a segunda divisão do campeonato pernambucano sendo terceiro colocado em 1998 e quinto em 1999. Em 2000, o Centro Limoeirense novamente fez boa campanha na série A2 do Pernambucano o que culminou em mais um vice-campeonato, deixando o título escapar para a Associação Garanhuense de Atletismo. Com a campanha do vicecampeonato, ganhou o direito ao acesso a primeira divisão no ano seguinte, mas não obtiveram bons resultados na série $A 1$, apenas cinco vitórias o que culminou em mais um rebaixamento (PRATES, 2015).

Em 2004, foi a melhor equipe da primeira fase da Copa Pernambuco, chegou a final com a vantagem do empate, mas mesmo jogando no José Vareda perdeu para a Desportiva Vitória, ficando como vice-campeão mais uma vez. Disputou também as edições da série A2 em 2005, ficando em 14ํ, 2007 ficou em $3^{\circ}$ e acabou promovido a primeira divisão do ano de 2008, em 2009 não fez boa campanha e acabou retornando a série A2 (PRATES, 2015).

Em 2013, o clube passou o período do centenário na Série $\mathrm{A} 2$. O ano foi de muita comemoração para a agremiação centrista, com festas e até celebração de missa durante a semana. O grande dia, um domingo, foi marcado por queima de fogos e um jogo festivo com o Campinense, então campeão da Copa do Nordeste. Motivos para comemorar 
no amistoso não faltaram, o alvirrubro do Agreste venceu por 3 a 0 , com direito a um sonoro "parabéns para você" cantado pelos adeptos após o apito final (PRATES, 2015).

Atualmente 0 Centro Limoeirense continua sua busca pelo sonho de retornar à primeira divisão do campeonato pernambucano, em 2018 o projeto passa pela disputa de todos os campeonatos promovidos pela FPF-PE desde as categorias de base sub 15 e sub 17, do futebol feminino adulto à série A2 do futebol adulto masculino. O objetivo é construir equipes formadas por atletas das cidades circunvizinhas, oportunizando os jogadores do interior pernambucano.

\section{CONCLUSÃO}

A memória Centrista merece ser lembrada pela sua riqueza e significado para o cenário esportivo pernambucano. Durante a pesquisa foram encontradas inúmeras dificuldades no decorrer do estudo, como a falta de registros (documentos e poucas fotos) relacionados ao clube. Mas, acreditamos que colaboramos com a valorização da história do clube, ao colocarmos em evidência alguns fatos que representam a memória centrista.

Após reconstruir algumas memórias do Centro Limoeirense, observamos peculiaridades que cercaram a trajetória construída pela equipe e seus participantes, seus feitos relevantes ou até mesmo de pouca expressão certamente enriqueceram a sua história e que é motivo de orgulho para seus adeptos. Foram também descritos os principais eventos da sua centenária vida, tendo a pretensão de preencher um lapso no campo da história do futebol pernambucano acerca uma equipe centenária.

Nesses 105 anos de história, o Centro Limoeirense se deparou e superou diversos obstáculos, os parceiros e a comunidade interiorana foram fundamentais para a sobrevivência do clube. Tendo sua história relacionada inicialmente ao futebol de várzea até alcançar a profissionalização adquiriu a simpatia de diversos torcedores e isto dá forças ao clube para continuar sua busca a elite do futebol estadual. Considerado o clube de futebol mais antigo do interior pernambucano, e o terceiro do estado, o Centro Limoeirense teve seus momentos altos e baixos, e uma trajetória longa e árdua, o clube só podia contar com o trabalho de profissionais esforçados que, na maioria das vezes, trabalhavam sem receber nada em troca, além da satisfação de participar de algo maior. Portanto, o Centro para o Limoeirense ganhe, empate ou perca dentro das quatro linhas é um clube que nunca perde a esperança pois consegue se adaptar e superar às dificuldades há mais de um século (PRATES, 2015).

\section{REFERÊNCIAS}

ANDRADE, J. N.; COSTA, B. Centro Limoeirense comemora 100 anos. Diário de Pernambuco, Recife, 15 set. 2013.2 Esportes. Disponível em: $<$ https://www.pe.superesportes.com.br/app/18,95/2013/09/15/noticia_interior,26237/centro-

limoeirense-comemora-100-anos.shtml>. Acesso em: 19 dez. 2016.

ANTUNES, F. M. Futebol de fábrica em São Paulo. 1992. 190 f. Dissertação (Mestrado em Sociologia) - Universidade de São Paulo, São Paulo.

CONFEDERAÇÃO BRASILEIRA DE FUTEBOL. Cadastro nacional de clubes de futebol. [Rio de Janeiro]: CBF, 2009. Disponível em: <https://conteudo.cbf.com.br/cdn/201303/document-20130319234423.pdf $>$. Acesso em: 20 out. 2017.

CONFEDERAÇÃO BRASILEIRA DE FUTEBOL. Cadastro nacional de estádios de futebol. [Rio de Janeiro]: $\quad$ CBF, 2016. Disponível em: <https://cdn.cbf.com.br/content/201601/20160122182359_0.pdf>. Acesso em: 20 out. 2017.camp CENTRO LIMOEIRENSE. Estatuto do Centro Limoeirense. Limoeiro: Centro Limoeirense, 2011. 23 p.

MAGALHÃES, G. R. Campeonato Pernambucano 1963. In: Futebol Nacional. 2018 Disponível em: $<$ https://futebolnacional.com.br/infobol/championship.jsp?code=4F7AE4790E7EC53271E845A273CD 67BD\&lang=pt_br>. Acesso em: 17 jun. 2018.

MÁXIMO, J. Memórias do futebol brasileiro. Estudos Avançados, Dossiê Memória. Instituto de Estudos Avançados da Universidade de São Paulo. São Paulo, v. 13, n. 37, p. 179-188, set./ dez. 1999.

MELLO, S. Um Clássico Centenário no Sertão de Pernambuco: Centro Limoeirense versus Colombo Sport Club. In: História do Futebol. [Recife]: [s. n.], 2018. Disponível em: <http://cacellain.com.br/blog/?p=116259>. Acesso em: 10 fev. 2018. 
MILLS, J. Charles Miller: o pai do futebol brasileiro. São Paulo: Panda, 2005.

PEREIRA, S. E. M. Uma breve história de Limoeiro. Olinda: Livro Rápido, 2013.

PRATES, L. F. Centro Limoeirense tenta se reerguer no futebol pernambucano. In: Medium. Limoeiro: s.n, 2015. Disponível em: <https://medium.com/@luisf_prates/centro-limoeirense-tenta-sereerguer-no-futebol-pernambucano-10626fdbbeb>. Acesso em: 19 dez. 2017.

PIRES, G. L. Breve introdução ao estudo dos processos de apropriação social do fenômeno esporte. Revista da educação física/UEM 9(1):25-34, 1998.

VILAÇA, A S. Histórias que Limoeiro conta. Rio de Janeiro: Arquimedes, 1971. 368 p.

ZIRPOLI, C. Um século do Centro Limoeirense, um século tentando existir. Diário de Pernambuco,

Recife, 15 set. 2013.2 Esportes. Disponível em:

<http://blogs.diariodepernambuco.com.br/esportes/2013/09/15/um-seculo-do-centro-limoeirense-umseculo-tentando-existir/>. Acesso em: 19 jan. 2017. 